\title{
Effects of Heat Treatment on the Properties of Mild Steel Using Different Quenchants
}

\author{
Ahaneku I. E. 1,*, A. R. Kamal ${ }^{2}$, O. A. Ogunjirin ${ }^{2}$ \\ ${ }^{1}$ Department of Agricultural and Bioresources Engineering, Federal University of Technology,Minna, +234 , Nigeria \\ National Centre for Agricultural Mechanization, (NCAM), Ilorin, +234, Nigeria
}

\begin{abstract}
This study was conducted in order to improve the mechanical properties of mild steel materials used as bolts and studs in coupling agricultural machinery following their frequent failure in service. Heat treatment at $900^{\circ} \mathrm{C}$ for four hours was done and six specimens of each were then quenched with different media used as the major source of strength enhancement. The universal testing machine (UTM) was utilized for the various mechanical tests. The results of the tests showed positive changes in the strength properties of the mild steel material, in terms of high tensile strength, toughness, ductility and hardness. Water quenched specimen has the highest tensile strength $\left(497.76 \mathrm{~N} / \mathrm{mm}^{2}\right)$, hardness value (138.27), toughness $(168.38)$ and bending at yield $\left(749.49 \mathrm{~N} / \mathrm{mm}^{2}\right)$. It a lso recorded the lowest ductility of $28.36 \%$ when co mpared with ductility values for other quenchants. These desirable qualities are needed for durability in service, especially for rugged agricultural operations like tillage. Water proved to be the best quenchant for ach ieving these desirable qualit ies among the quenching media used.
\end{abstract}

Keywords Heat Treatment, Tillage, Mild Steel, Failure, Quenchants

\section{Introduction}

The subject of mechanical testing of materials is an important aspect of engineering practice. Today, more attention is being given to the interpretation of test results in terms of service performance, as well as giving reliable indications of the ability of the material to perform certain types of duty. Mechanical tests are also employed in investigational work in order to obtain data for use in design to ascertain whether the material meets the specifications for its intended use[1]. For this purpose, the tests should provide the information accurately, rapidly and economically.

Heat treat ment, an operation, or co mb ination of operations, involving the heating and cooling of a metal or an alloy in the solid state, is another method of obtaining certain desirable conditions in metals. [2] reported the effect of heat-treatment on the properties of case-hardening steel with $0.17 \%$ carbon, $0.24 \%$ silicon, $0.72 \%$ manganese and $0.04 \%$ sulphur and phosphorus. The result showed an increase in Brinell hardness, yield point and ultimate tensile stress but a slight decrease in percentage elongation when the steel was quenched in water after being normalized at $920^{\circ} \mathrm{C}$, reheated and quenched in water fro $m 760^{\circ} \mathrm{C}$. Hardness testing is often used to evaluate heat treatments and can be used as an

* Corresponding author:

drahaneku@yahoo.com (Ahaneku, I.E.)

Published online at http://journal.sapub.org/f

Copyright (C) 2012 Scientific \& Academic Publishing. All Rights Reserved approximation for tensile strength[3].

In agricultural production operations, some general-purpose machine elements are used extensively on tractors as well as on tillage implements. Typical of such elements are fasteners like bolts and studs used to couple implement gangs unto the implement frame.These elements during field operations are subjected to fatigue loading and tend to fail mainly by shear and bending. Bolts and studs are supposed to be made from mild steel (up to $0.25 \%$ carbon) with characteristic toughness and ductility. These elements, however, tend to fracture with repeated or frequent bending cycles. According to[4], the performance and reliability of an engineering structure or assembly is a function of the quality of the various components. Failure of any component of an equipment may have serious consequences on the functionality of the equipment or machine.Some common causes of failure include design deficiencies, material selection, material imperfections, a mbiguous manufacturing processes and fatigue[3].

The available studs and bolts found in the local markets in Nigeria and often used for coupling on tractor implements are of the inferior grade that fail too frequently. Their specifications are often not known which makes it impossible to predict their suitability for the intended task. The producers of these studs probably machine them out from any cheap grade of iron or steel material without consideration for their intended applications and service life.Quenching is usually used to obtain a required micro structure, hardness, strength or toughness, while minimizing 
residual stresses, distortion and the possibility of cracking.Quenching effectiveness is dependent upon steel composition, type of quenchant or quenchant use conditions [5].

Studies have shown that low carbon steel such as mild steel can be strengthened through heat treatment, while quenching after heat treatment improves the mechanical properties of the steel material[6, 7, 8, 9]. For most metallic materials, the high-cycle resistances are dominated by the strength and ductility, respectively[10]. These desirable attributes can only be achieved through appropriate heat treatment and quenching. Several quenchants have been us ed for steel hardening among which are water, air, oil, brine and superquench. Each has its merits and demerits. Superquench according to[11] is a heavy brine solution with greater percentage of water by weight. Brine has some beneficial effects such as fast quenching rates than water and reduction in non-uniform heat transfer during quenching. However, it has a major disadvantage of being corrosive both to the quenched material and the equip ment used[8]. This gives rise to more frequent equipment shut downs and the associated higher maintenance costs. Accordingly, brine was not used in this study.

Most research efforts on the effects of heat treatment on the mechanical properties of steel materials were carried out in more developed countries where standards are maintained $[12,4,8,13,14]$. This calls for more concerted efforts in the developing countries like Nigeria where substandard materials saturate the markets.

\section{Objectives of the Study}

The objectives of this study were to: (i) investigate the effects of heat treatment on the mechanical properties of locally available mild steel studs using different quenchants, and (ii) recommend the most appropriate quenchant from the standpoint of strength and economy.

\section{Methods}

Thirty samples of the stud (M20) were obtained from the local market for the purpose of this investigation. Fifteen (15) Standard test specimens were machined, each for tensile and bend tests, respectively. The stud sample and test specimens are shown in figures 1 and 2.Twenty-four specimens were case hardened by pack carburizing method, while the remaining six samples were not subjected to any heat treatment to serve as control.The method involved placing the samples in a steel box along with $80 \%$ wood and $20 \%$ barium carbonate. The wood acted as the carburizing material while the barium carbonate was the energizer for promoting rapid action on the steel. The specimens were placed in an electric furnace and heated at $900^{\circ} \mathrm{C}$ for four hours. Six specimens each was then quenched using four different media viz.: air, furnace, o il and water.
As a result of prolonged heating at a high temperature in the carburizing operation, both the core and the case were expected to exhibit overheated structure, which would be unsatisfactory in service, especially under severe conditions. The specimens were then further heat-treated to refine the core, and also to refine and harden the case. Core refining was accomplished by heating just above the upper critical point for the core $\left(870^{\circ} \mathrm{C}\right)$, soaking for 30 minutes and then quenched using the quenchants described above. The refining and hardening of the case was produced by quenching the specimens fro $760^{\circ} \mathrm{C}$.

After the heat treatments, 15 specimens each were then subjected to uniaxial tensile and 3-point flexural (bend) tests, respectively using the Testometric Universal Testing Machine (Ax model M500-50KN) with $500 \mathrm{kgfload}$ cell at a constant cross-head speed.A Personal Computer was used to record the output.Brinell hardness test which is usually associated with decarburization on the measured surface hardness[15]was evaluated using the empirical relationship between tensile strength and Brinell Hardness Number(BHN) for steels [16] as:

$$
k \times(B H N)=\text { Tensilestrength }\left(M N / m^{2}\right)
$$

Where $\mathrm{k}$ is a constant ranging from $3.4-3.9$ for steels.An average value of 3.6 for $\mathrm{k}$ was used for the evaluation of $\mathrm{BHN}$ in this study.

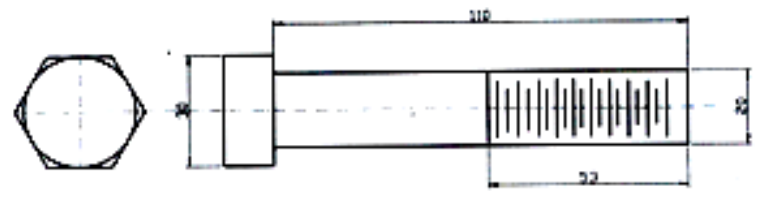

Figure 1. Stud Sample

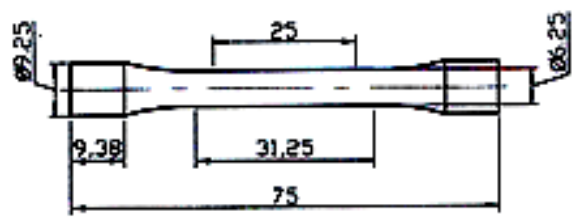

Figure 2a. Specimen for tensile test

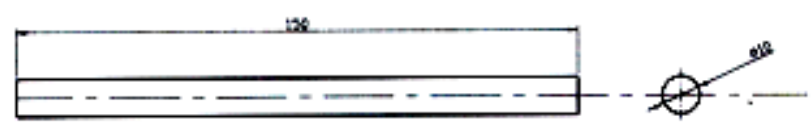

Figure 2b. Specimen for bend test (units: $\mathrm{mm}$ )

\section{Results}

The following mechanical properties were obtained from the tests:

(i) Tensile Strength (T.S): is the load required to fracture unit area of the metal.

(ii) Yield Strength (Y.S): is a measure of the onset of plastic deformation. ( $0.2 \%$ permanent extension). 
(iii) Percentage Elongation (E.L) in gauge length: is a measure of the ductility of the material.

(iv) Percentage reduction in cross-sectional area $\left(\mathrm{R}_{\mathrm{a}}\right)$ measured at the point of fracture is also related to ductility. Very ductile materials are considerably reduced in cross section before they break.

(v) Young's Modulus of Elasticity (E): is the stiffness, rigidity, or springiness of a material. It is the slope of the linear portion of the stress/strain graph for the material. It is also the ratio between the stress applied and the elastic strain it produces. (vi) Toughness (Er): is the energy absorbed by the material before it fractures. This is the area under the force extension or stress - strain curve up to rupture point (N.mm).

(vii) Brinell Hardness Number (BHN): indicates the surface hardness of the material.

The stress-strain curves for the tensile tests are shown in figures 3 to 5 , whilefigures 6 to 8 depict the load-deflection curves for the bending tests. The summary data of the tensile and bend tests are presented in table 1.

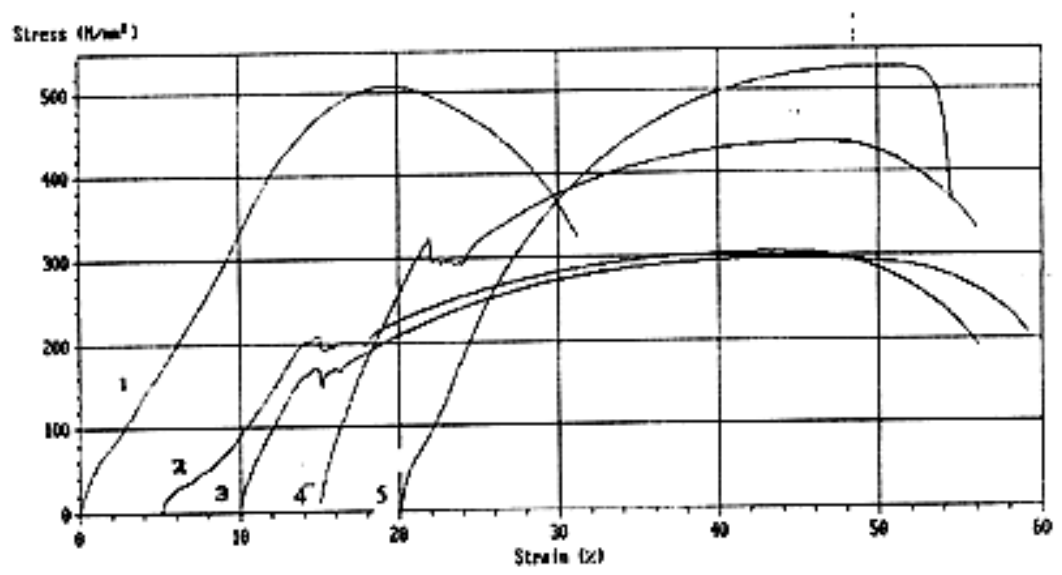

Figure 3. Tensile stress-strain curves for replicate 1 of test sample using different quenchants

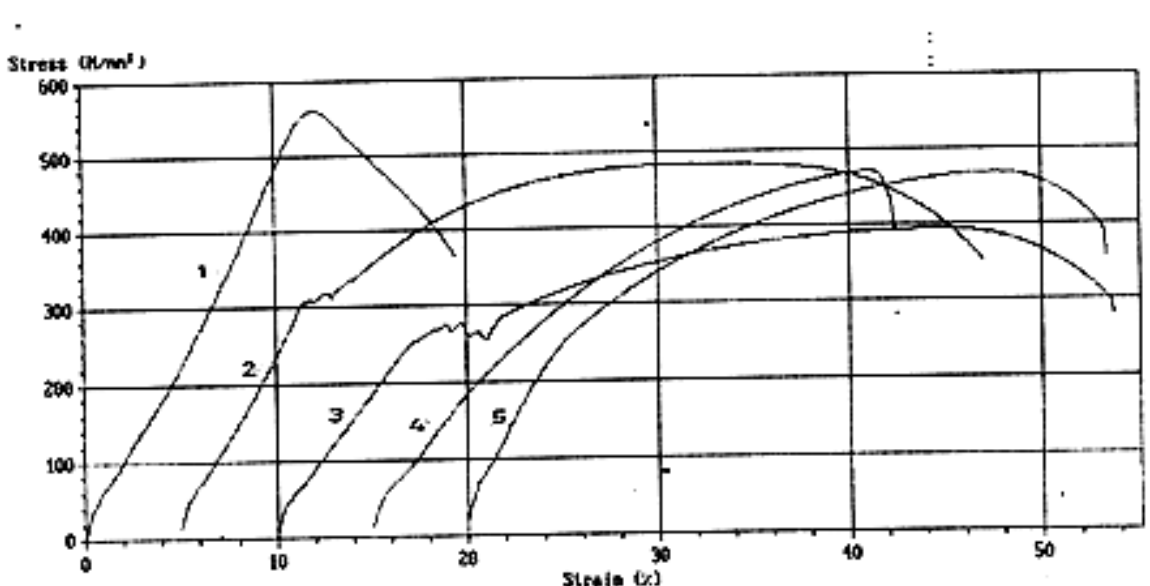

Figure 4. Tensile stress-strain curves for replicate 2 of test sample using different quenchants

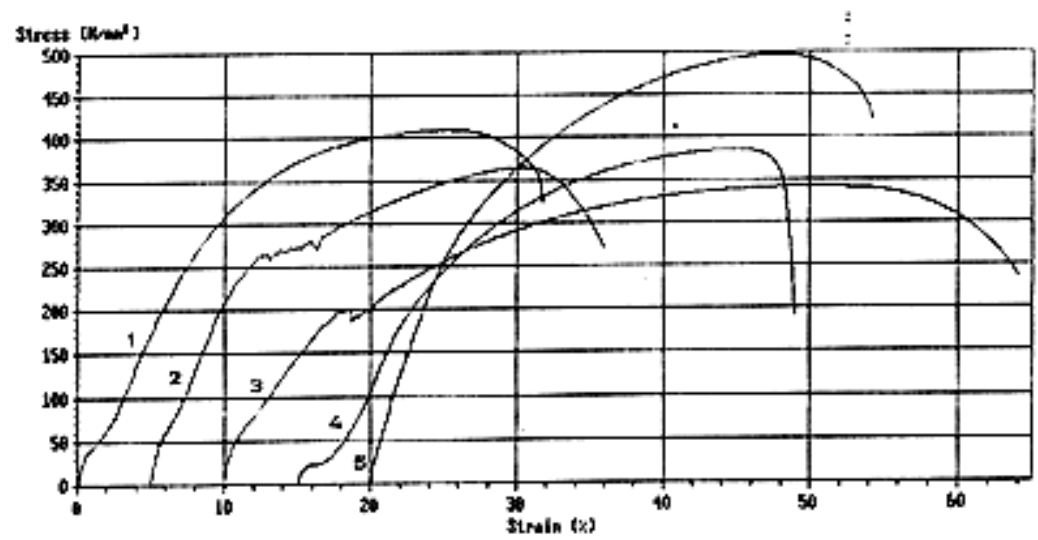

Figure 5. Tensile stress-strain curves for replicate 3 of test sample using different quenchants1-Control; 2-Air; 3-Furnace; 4-Oil; 5-Water 


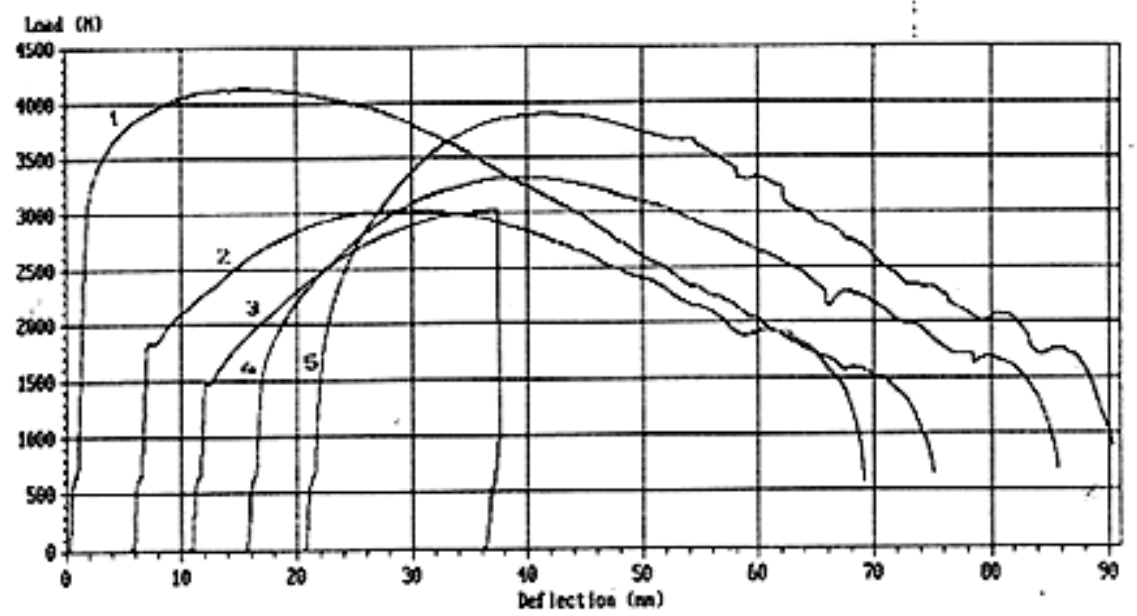

Figure 6. Load-deflection curves for replicate 1 of test sample using different quenchants

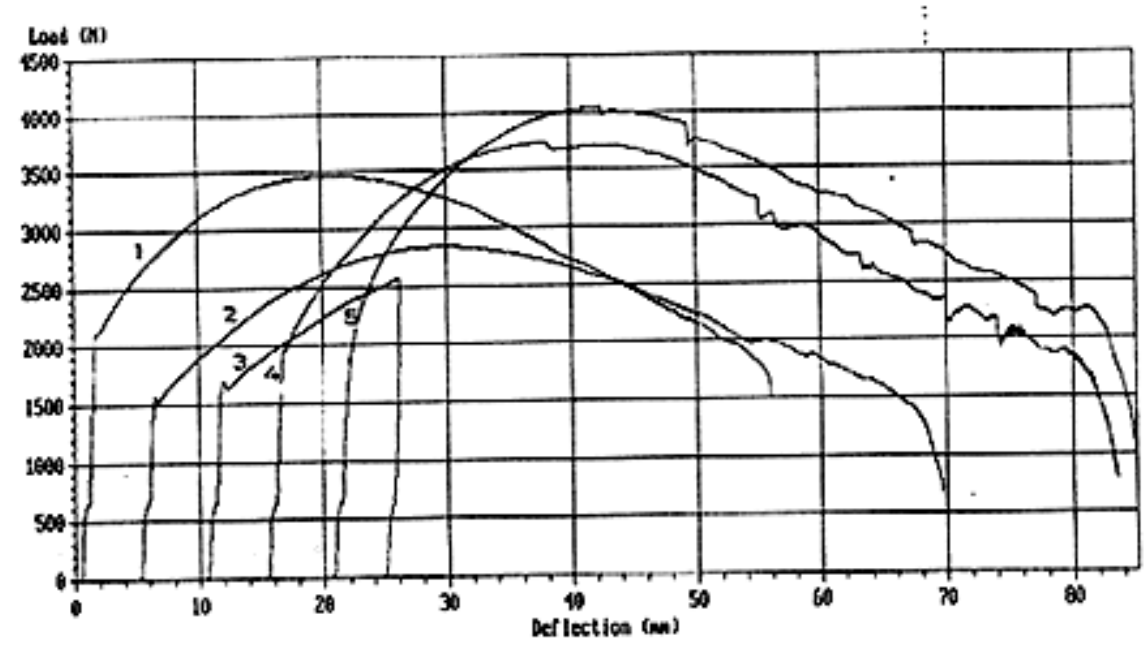

Figure 7. Load-deflection curves for replicate 2 of test sample using different quenchants

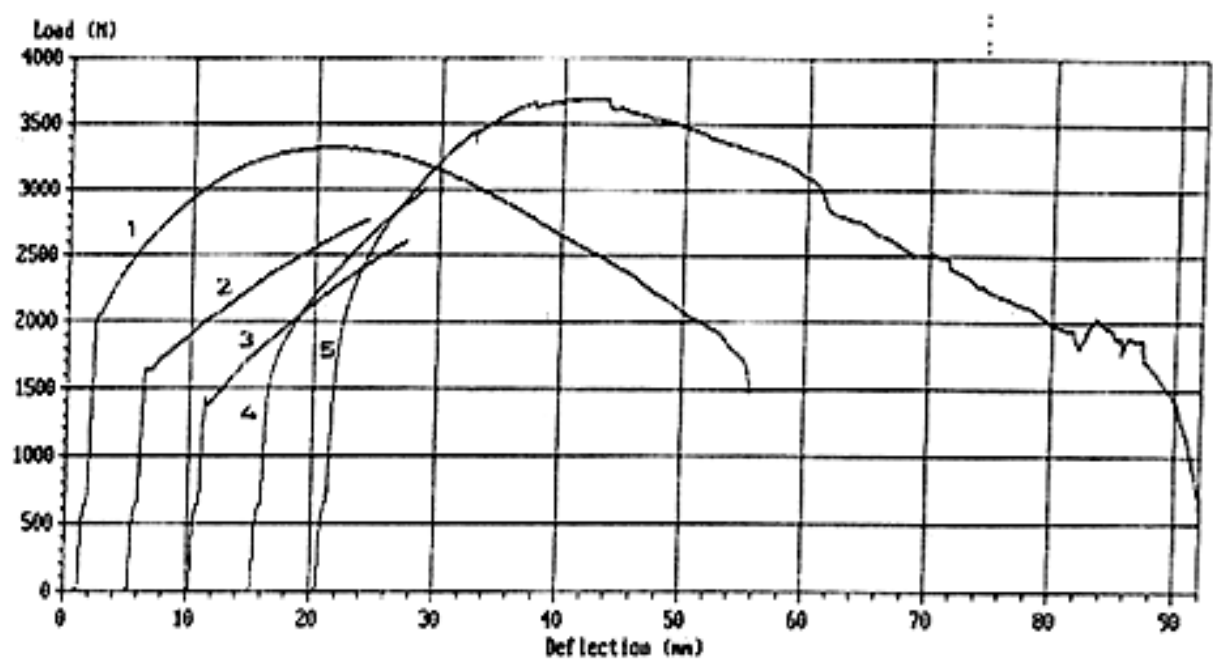

Figure 8. Load-deflection curves for replicate 3 of test sample using different quenchants. 1-Control; 2-Air; 3-Furnace; 4-Oil; 5-Wat er 
Table 1. Summary data of treatment effects on mechanical properties of mild steel

\begin{tabular}{|c|c|c|c|c|c|c|c|c|c|}
\hline \multirow[b]{2}{*}{ Quenchant } & \multicolumn{7}{|c|}{ Tensile Test } & \multicolumn{2}{|c|}{ Bend Test } \\
\hline & 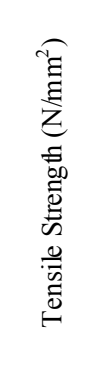 & 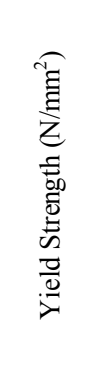 & 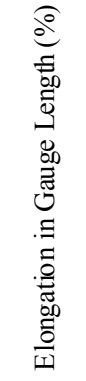 & 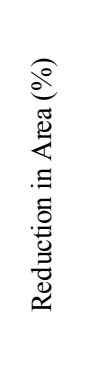 & 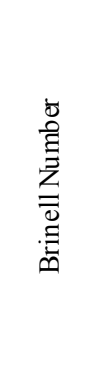 & 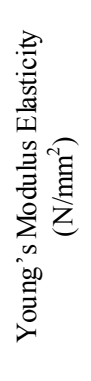 & 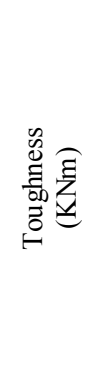 & 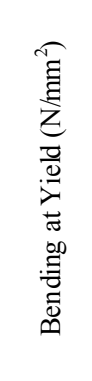 & 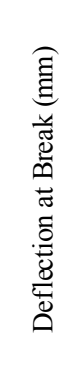 \\
\hline Control & 492.99 & 492.48 & 18.89 & 57.47 & 136.94 & 38.44 & 136.32 & 743.97 & 60.16 \\
\hline Air & 384.35 & 258.72 & 30.14 & 71.54 & 106.76 & 34.03 & 86.53 & 139.68 & 51.31 \\
\hline Furnace & 343.96 & 214.88 & 35.77 & 72.02 & 95.54 & 29.43 & 33.38 & 215.11 & 20.37 \\
\hline Oil & 431.17 & 392.09 & 28.94 & 56.17 & 119.77 & 35.92 & 101.88 & 530.41 & 51.02 \\
\hline Water & 497.76 & 497.60 & 28.36 & 58.82 & 138.27 & 43.45 & 168.38 & 749.49 & 69.12 \\
\hline
\end{tabular}

\section{Discussions}

From the stress-strain curves (figures 3-5), it can be inferred that the control (specimen 1) did not yield until it attained the tensile strength.Specimen 5 (water quenched) followed a similar trend to that of specimen 1, except that it yielded at a higher tensile strength.Thus, the heat treated and water quenched specimen exhibited superior mechanical properties over the original untreated specimen in terms of higher tensile and fatigue strengths. This result is consistent with the report of[17] that one of the major adjustable parameters in heat treatment that affect the mechanical properties of materials, including the yield strength and hardness is the quenching media.

The results of the treatment effects on mild steel shown in table 1 indicate that specimen 5 (water quenched) proved superior to other specimens quenched in air, furnace and oil, respectively with respect to high strength properties, Brinell hardness, toughness and yield points. This result is in agreement with the findings of[12] and[7] that hardness and toughness exhib it mirror behaviour. In contrast, the furnace and air-cooled treatments proved better than other treatments in ductility. This is as a result of their higher values of elongation (peak strain) and percentage reduction in area. Among the treatments, oil quenching proved to be the poorest media in terms of ductility. The high cost of oil will also discourage its use as a quenching media coupled with its poor performance.

The stress and strain at peak for both the control and the water quenched specimen were the same for the corresponding stress and strain at yield (figures 3 and 4). However, the water quenched treatment gave higher values of stress and strain at yield than the original specimen (figure 5). This implies that the water-quenched samples are better in terms of ductility than the original specimen.The achievement of the difficult combination of strength and ductility gives the water-quenched sample an edge over all other treatments. Earlier works $[10,11]$ indicate that for most metals, the high-cycle resistances are dominated by strength and ductility. The results of this study shows that water quenched samples are better than the other quenchants in terms of strength and ductility. There fore, water remains the most common quenchant. More importantly, water is inexpensive, easy to use and has minimal safe handling or disposal considerations [8].

In terms of strength and hardness, the order of performance is as follows:Water-cooled $>$ Control $>0$ il cooled $>$ Air cooled $>$ Furnace cooled. Figures 6 to 8 and table 1 also show that the water quenched specimen gave the highest values of bending strength and deflection at break; thus, confirming the consistency of this method of cooling in improving the mechanical properties of mild steel as was the case in the tensile tests.These results are in agreement with the findings fromsimilar studies reported by[2]. When cost of quenching is put into consideration, it becomes obvious to conclude that using water, as a quenching media is more cost effective.

\section{Conclusions}

Tests were carried out to determine the effects of heat treatment on the mechanical properties of locally available mild steel studs used for agricultural operations using different quenchants. The findings from the study showed that water quenched specimens proved superior to other specimens quenched in air, furnace and oil, respectively with respect to high strength properties, Brinell hardness, toughness and yield point. Water being relatively more readily available than other quenchants except air, easy to use and safe to handle is preferred. It is therefore concluded that from the standpoint of strength and economy that water quenching should be used for heat-treating mild steel components for coupling agricultural machinery. 


\section{REFERENCES}

[1] W. F. Smith. 1990. Principles of Materials Science and Engineering, McGraw-Hill.

[2] E.C. Rollason. 1964. Metallurgy for Engineers. Edward Arnold Publishers Ltd., Great Britain.

[3] S. Mackenzie. 2008. Overview of the Mechanisms of Failure in heat Treated Steel Components. Failure Analysis of Heat Treated Steel Components (\#05113G). www.asmiternational .org Assessed on 31st December, 2010.

[4] A. Vazdirvanidis, G. Pantazopoulos and A. Louvaris. 2009. Failure Analysis of a Hardened and Tempered Structural Steel (42CrMo4) Bar for Automotive Applications. Engineering Failure Analy sis. 16 pp 1033-1038.

[5] H. W. Walton and R. Wallis. 2010. Heat Treating: Proceedings of the 18th Conference on Quenchant Selection including the Liu Dai. www.asmiternational.org. Assessed on 31st December, 2010.

[6] B. Eghbali. 2010. Study on the Ferrite Grain Refinement during Intercritical Deformation of a Micro alloyed Steel. Mat. Sci. Eng. A -Struct. 527(15): 3407-3410.

[7] P. O. Offor, C. C. Daniel and D. O. N. Obikwelu. 2010. Effects of various Quenching Media on the Mechanical Properties of Intercritically Annealed $0.15 \mathrm{Wt} \% \mathrm{C}$ $0.43 \mathrm{Wt} \% \mathrm{MnSteel}$. Nigerian Journal of Technology, Vol. 29 No 2, pp 76-81.

[8] T. Korad, M. Polboon, N. Chumchery and J. Pearce. 2011. Improving Quench Hardening in low Carbon Steel. Journal of Metals, Materials and Minerals, Vol 21 No 1 pp 67-74.

[9] S. H. Park, S. Hong, Y. S. Chun, Y. Lee and C. S. Lee. 2012. High-cycle fatigue characteristics of non-heat-treated steels developed for bolt applications. Materials Science and Engineering A550: 118-124.

[10] S. G. Hong, S. H. Park, and C. S. Lee. 2010. Journal of Material Research 25: 784.

[11] J. Dempsey. 2012. Quenchants: air, brine, water, oil, synthetics and superquench, FQAs webboard on quenchants in internet resource for blacksmith. (Online). Available: http://www.anvilfire.com[May, 2012].

[12] S. Z. Qamar. 2009. Effects of Heat Treatment on Mechanical Properties of HII Tool Steel. Journal of Achievement in Materials and Manufacturing Engineering, Vol. 35(2) pp 115-120.

[13] S. S. Zhang, M. Q. Li, Y. G. Liu, J. Luo and T. Q. Liu. 2011. The Growth Behavior of Austenite Grain in the Heating Process of 300M Steel. Mat. Sci. Eng, A;528: 4967-72.

[14] W. Lu, Y. Shi, Y. Lei and X. Li. 2012. Effect of electron beam welding on the microstructures and mechanical properties of thickTC4-DT alloy. Mater Des(34): 509-15.

[15] W. Yin, X. J. Hao, A. J. Peyton, M. Strangwood and C. L. Davis. 2010. Measurement of Decarburization of Steel Rods with an Electromagnetic Sensor using an Analytical Model. NDT \& E Int. 43(8): 667-670.

[16] P.P Benham and F.V. Warnock. 1978. Mechanics of Solids and Structures. Pitman Publishing Ltd., London, pg. 480.

[17] Technology Products Processes. 2006. Yield Strength and Heat Treatment. TPP Information Centre 